\title{
The prevention and treatment of COVID-19 and related development during pandemic
}

\author{
Chin-Kun Wang ${ }^{\mathrm{a}}$, Yuan-Ti Lee ${ }^{\mathrm{b}, \mathrm{c}, \mathrm{d}}$, Chao-Bin Yehe,f,g, Chi-Ho Chan ${ }^{\mathrm{g}, \mathrm{h}^{*}}$ \\ aDepartment of Nutrition, Chung Shan Medical University, 110, Sec. 1, Jianguo North Road, Taichung City, Taiwan, ROC \\ bInstitute of Medicine, Chung Shan Medical University, 110, Sec. 1, Jianguo North Road, Taichung City, Taiwan, ROC \\ 'School of Medicine, Chung Shan Medical University, 110, Sec. 1, Jianguo North Road, Taichung City, Taiwan, ROC \\ ${ }^{\mathrm{d} D i v i s i o n}$ of Infectious Diseases, Department of Internal Medicine, Chung Shan Medical University Hospital, 110, Sec. 1, Jianguo North \\ Road, Taichung City, Taiwan, ROC \\ eDepartment of Emergency Medicine, School of Medicine, Chung Shan Medical University, 110, Sec. 1, Jianguo North Road, Taichung \\ City, Taiwan, ROC \\ fDepartment of Emergency Medicine, Chung Shan Medical University Hospital, 110, Sec. 1, Jianguo North Road, Taichung City, Taiwan, \\ ROC \\ gDepartment of Medical Research, Chung Shan Medical University Hospital, 110, Sec. 1, Jianguo North Road, Taichung City, Taiwan, \\ ROC \\ hDepartment of Microbiology and Immunology, Chung Shan Medical University, 110, Sec. 1, Jianguo North Road, Taichung City, Taiwan, \\ ROC \\ *Corresponding author: Chi-Ho Chan, Department of Microbiology and Immunology, Chung Shan Medical University, 110, Sec. 1, \\ Jianguo North Road, Taichung City, Taiwan, ROC. Tel: +886 424730022 ext 12022; Fax: 8864 24727178; E-mail: chiho@csmu.edu.tw \\ DOI: $10.31665 /$ JFB.2021.16290 \\ Received: September 16, 2021; Revised received \& accepted: December 23, 2021 \\ Citation: Wang, C.-K., Lee, Y.-T., Yeh, C.-B., and Chan, C.-H. (2021). The prevention and treatment of COVID-19 and related develop- \\ ment during pandemic. J. Food Bioact. 16: 25-33.
}

\begin{abstract}
When the outbreak of human novel coronavirus was first reported in Wuhan, China at the end of 2019, the epidemic spread rapidly around the world and finally became a pandemic in 2020. In order to seek effective drugs to treat the COVID-19 infected patients for emergent use and for the disease prevention, researchers examined numerous existed antiviral drugs that may have the potential for COVID-19 treatment. At the same time, antibody treatment and vaccines development were ongoing simultaneously. The aim of this review is to introduce antibody therapy, vaccine development and potential antiviral treatments on COVID-19 and to discuss the future perspective on the COVID-19 pandemic.
\end{abstract}

Keywords: SARS-CoV-2; COVID-19; Antibody therapy; Vaccine development; Antiviral drugs.

\section{Current status of Covid-19}

The outbreak of novel coronavirus (2019-nCoV), was first reported in Wuhan, Hubei province, China since December, 2019 (Huang et al., 2020). The virus was renamed severe acute respiratory syndrome coronavirus type 2 (SARS-CoV-2) based on phylogenetic analysis to differentiate it from the first outbreak caused by the SARS-CoV in 2003. At the same time the related disease of SARS-CoV-2 was renamed COVID-19 by World Health Organiza- tion (WHO). Due to its rapid spreading via international travelling of people and serious respiratory symptom in human population, WHO declared COVID-19 a public health emergency of international concern in 2019 (Huang et al., 2020; Wang et al., 2021a). Till now, more than two hundred million of confirmed cases and nearly four millions and six hundred thousand people died from COVID-19 infection. Meanwhile, several types of COVID-19 vaccines are produced for people to establish their immunity against SARS-CoV-2 globally. In fact, abundant of antiviral drugs and 
passive immunization therapy have been tried to treat COVID-19 patients, before the vaccines production, especially application on those severe COVID-19 patients. However, cases and number of death are still increasing on every day around the world. The most probably reason is due to the emerging of numerous of SARS$\mathrm{CoV}-2$ variants in different countries. Even some of the variants has been reported that they had the ability to break through patients' immunity even after they were fully vaccination. In this review, we focused on the features of SARS-CoV-2 and its variants, vaccine development, antibody therapy and potential antiviral drugs on COVID-19.

\section{Features of SARS-CoV-2}

SARS-CoV-2 is an enveloped, single positive strand RNA virus, belongs to the family coronaviridae, genus betacoronavirus according to the update recommendation of the International Committee on Taxonomy of Viruses (ICTV) (Shchelkanov et al., 2020). Other viruses belong to this genus includes SARS-CoV, MERS$\mathrm{CoV}$, two human coronaviruses (OC43 and HKU-1) and murine hepatitis virus (MHV) (Fung and Liu, 2019; Malik, 2020; Velavan and Meyer, 2020).

The genome length of SARS-CoV-2 is about 30 kilobase. The organization of the genome includes two open reading frames (i.e. ORF1a and ORF1b) start from $5^{\prime}$ to $3^{\prime}$ in which encodes a series of non-structural proteins and enzymes. Next to the ORFs are those structural genes (i.e. S, E, M, and N) which encode spike (S), envelope protein $(\mathrm{E})$, matrix protein $(\mathrm{M})$, and nucleoprotein $(\mathrm{N})(\mathrm{Bah}-$ rami and Ferns, 2020; Lu et al., 2020).

Briefly, the SARS-CoV-2 enter the host cell through endocytosis by binding host angiotensin-converting enzyme 2 (ACE-2) receptor with the $\mathrm{S}$ protein on the envelope of the virus. After cleavage of the S1-S2 domain of the S protein by TMPRSS2, a cysteine protease, the virus enters into the cytoplasm of the host cell by fuses its envelope to the cell membrane and forms an endosome. After uncoating, the viral genome is released into the cytoplasm of the host cell, and the genome is translated into replicase polyprotein, PP1a, PP1ab and RNA-dependent RNA polymerase (RdRp). Through genome replication and a series of protein translation, the progeny virus is released by exocytosis and continue to infect other host cells or spread from respiratory tract to surroundings (Trougakos et al., 2021; V'kovski et al., 2021).

Just like other RNA virus, one of characteristic of SARS-CoV-2 is its RNA-dependent RNA polymerase lacking the proofreading during genomic RNA replication. After the virus infects the host cells, the genomes of the progeny viruses are not identical with each other and that of the parent virus. All the progeny viruses form a subpopulation of viruses that is called quasispecies (Gao et al., 2021; Jary et al., 2020). In addition, after virus infection, host's body will produce specific antibodies to neutralize the viruses via adaptive immune response. Despite of eliminate the virus, host immune response always prompt the virus to produce more variants under the selective pressure (Eskier et al., 2020; Presti et al., 2020). As a result, variants of SARS-CoV-2 continuously emerges from the patients around the world. All these variants have different phenotypes such as increasing of their transmissibility, increasing of disease severity and mortality in patients and decreasing the sensitivity from neutralizing effect of antibody after vaccination. For this reason, WHO designated these types of variants as the variants of concern (VOC) (Duong, 2021). In addition, there are other variants have certain mutations found in particular genes, i.e. S protein or other regions of the virus genome and they have possibility to affect public health in future. WHO also designated them as the variants of interest (VOI) (Chakraborty et al., 2021a; Konings et al., 2021). For most update information, a new SARSCoV-2 variant, named Omicron was announced on November 26, 2021 by WHO. Surprisingly, the speed of this variant is faster than other known circulated variants (He et al., 2021). The characteristics of Omicron might include increase of infectivity, vaccine breakthrough, antibody resistance and drug resistance (Chen et al., 2021) (Table 1).

\section{Vaccine development}

Nowadays, there are more than 300 vaccine candidates has being developed according to the information of WHO since the beginning of the COVID-19 pandemic. On September, 2021, totally 117 vaccines are being test in different phases on clinical trials while 185 vaccines are in subclinical development (Shrotri et al., 2021). The vaccine candidates are still increasing. Among them, there are 18 vaccines were approved for emergency use authorization (EUA) by at least one regulatory authority 2021 (Ndwandwe and Wiysonge, 2021). Among these vaccines, Oxford/AstraZeneca ChAdOx1-S (England), BioNTech/Pfizer BNT162b2 (German), Moderna mRNA-1273 (USA), and MVC-COV1901 (Taiwan) are allowed to use in Taiwan.

Ten platforms are adopted for COVID-19 vaccines developments currently. It can be divided into two categories, the classical platforms and novel platforms. The classical platforms include protein subunit (PS) (Heath et al., 2021; Ryzhikov et al., 2021; Hsieh et al., 2021), inactivated whole virus (IV) (Ariamanesh et al., 2021; Organization, 2021; Palacios et al., 2020), virus-like particle (Burgos-Salcedo, 2021; Park et al., 2020), and live attenuated virus (Wang et al., 2021a; Qian et al., 2021). The novel platforms include non-replicating virus vector (NRVV) (Cao et al., 2021; Choo and Teo, 2021; Knoll and Wonodi, 2021; Sadoff et al., 2020), DNA (Nishikawa et al., 2021; Tebas et al., 2021), mRNA (Chagla, 2021; Teo, 2021), replicating virus vector (Misra et al., 2021), replicating virus vector plus antigen presenting cell (Haidere et al., 2021), non-replicating virus vector plus antigen presenting cell (van Riel and de Wit, 2020; Zhang et al., 2020). Four out of 10 platforms (i.e. PS, NRVV, RNA and IV) are being used to produce the COVID-19 vaccines massively and supplying globally for the prevention and even termination of COVID-19 pandemic (Heinz and Stiasny, 2021).

Table 2 summarized the platforms on vaccine development and the types of vaccines for current used for the prevention of COVID-19.

\section{Antibody therapy}

When Emil von Behring and Shibasaburo Kitasato discovered that the serum of animals immune to diphtheria or tetanus possessed anti-toxic activity, i.e. antibody in 1890s, it became a useful method to treat so many infectious diseases (Ripoll et al. 2021). Paul Ehrlich first used passive immunotherapy by developed antiserum to treat diphtheria. With the continuous development of immunology, passive immunotherapeutic included hyperimmune immunoglobulin from immunized animals and convalescent plasma from recovery patients. Especially during sudden outbreak of particular viral diseases such as SARS, MERS and avian influenza, etc., when there were lacking of both 
Table 1. Variants of SARS-CoV-2

\begin{tabular}{|c|c|c|c|}
\hline Lineage & $\begin{array}{l}\text { Place of } \\
\text { emergence }\end{array}$ & $\begin{array}{l}\text { Date of } \\
\text { emergence }\end{array}$ & Phenotypes \\
\hline \multicolumn{4}{|l|}{ Reference sequence } \\
\hline Wuhan-Hu-1 & China & Dec 2019 & Pneumonia (Ciotti et al., 2019) \\
\hline \multicolumn{4}{|c|}{ Variants of concern (VOC) } \\
\hline Alpha & UK & Sep 2020 & Increase transmissibility, severity and mortality (Aleem et al., 2021) \\
\hline Beta & South Africa & Aug 2020 & Increase transmissibility, reduce virus neutralization ability of antibody therapy \\
\hline Gamma & Brazil & Jul 2020 & Reduce virus neutralization ability of antibody therapy \\
\hline Delta & India & Dec 2020 & More transmissible than Alpha variant, vaccine is less effective \\
\hline Omicron & South Africa & Nov 2021 & More transmissible than other variants, vaccine is less effective \\
\hline \multicolumn{4}{|c|}{ Variants of interest (VOI) } \\
\hline Epsilon & USA & Sep 2020 & $\begin{array}{l}\text { Increase transmissibility, reduce virus neutralization } \\
\text { ability of antibody therapy (Arav et al., 2021) }\end{array}$ \\
\hline Zeta & Brazil & Oct 2020 & $\begin{array}{l}\text { Potential reduction in neutralization by antibody treatments and vaccine sera } \\
\text { (Panzera et al., 2021) }\end{array}$ \\
\hline Eta & Worldwide & Dec 2020 & $\begin{array}{l}\text { Potential reduction in neutralization by antibody treatments and vaccine sera } \\
\text { (Ozer et al., 2021; Pereira et al., 2021) }\end{array}$ \\
\hline Theta & Philippines & Jan 2021 & $\begin{array}{l}\text { Potential reduction in neutralization by antibody treatments and vaccine sera } \\
\text { (Ferraz et al., 2021) }\end{array}$ \\
\hline lota & USA & Nov 2020 & $\begin{array}{l}\text { Lower susceptibility to the combination bamlanivimab-etesevimab monoclonal } \\
\text { antibody treatment (Mahase, 2021a) }\end{array}$ \\
\hline Kappa & India & Oct 2020 & (Chakraborty et al., 2021b; Kumar et al., 2021) \\
\hline Lambda & Peru & Dec 2020 & $\begin{array}{l}\text { Increase transmissibility, evasion from neutralizing antibodies, resistance to } \\
\text { antiviral immunity (Kimura et al., 2021; Romero et al., 2021) }\end{array}$ \\
\hline
\end{tabular}

anti-viral drugs and vaccines in a short time. Passive immune therapy by using neutralization antiserum from recovered patients became a useful strategy for emergency use and lifesaving
(Gupta et al., 2020). Especially in the severe cases of COVID-19 patients, convalescent serum and monoclonal antibody are the two main strategies in antibody therapy.

\section{Table 2. Platforms of vaccine development on COVID-19*}

\begin{tabular}{|c|c|c|c|}
\hline Type of platform & Example of candidate vaccines & $\begin{array}{l}\text { Number of } \\
\text { doses required }\end{array}$ & $\begin{array}{l}\text { Route of ad- } \\
\text { ministration }\end{array}$ \\
\hline Inactivated whole virus (IV) & Sinovac, Beijing/Sinopharm BBIBP-CorV, Sinovac CoronaVac & 2 & IM \\
\hline Protein subunit (PS) & $\begin{array}{l}\text { Novavax NVX-CoV2373, Vector Institute } \\
\text { EpiVacCorona, MVC-COV1901 }\end{array}$ & 2 & IM \\
\hline Virus-like particle (VLP) & Medicago CoVLP & 2 & $\mathrm{IM}$ \\
\hline Live attenuated virus (LAV) & Covi-Vac, MV-014-212 & $1-3$ & IN \\
\hline Non-replicating virus vector (NRVV) & $\begin{array}{l}\text { Oxford/AstraZeneca ChAdOx1-S, Cansino Ad5-nCoV, } \\
\text { Gamaleya Gam-COVID-Vac/Sputnik V, Janssen Ad26.COV2.S }\end{array}$ & $1-2$ & $\mathrm{IM}$ \\
\hline DNA & Inovio INO-4800, AnGes AG0302-COVID19 & 2 & $\mathrm{ID} / \mathrm{IM}$ \\
\hline mRNA & BioNTech/Pfizer BNT162b2, Moderna mRNA-1273 & 2 & $\mathrm{IM}$ \\
\hline Replicating virus vector (RVV) & AdCLD-CoV-19 & 1 & $\mathrm{IM}$ \\
\hline $\begin{array}{l}\text { Replicating virus vector plus } \\
\text { antigen presenting cell (RVV+APC) }\end{array}$ & Dendritic cell vaccine AV-COVID-19 & 1 & IM \\
\hline $\begin{array}{l}\text { Non-replicating virus vector plus } \\
\text { antigen presenting cell (NRVV+APC) }\end{array}$ & LV-SMENP-DC & 1 & SC \& IV \\
\hline
\end{tabular}

*Part of information was adopted from WHO web site: Draft landscape of COVID-19 candidate vaccines. https://www.who.int/publications/m/item/draft-landscape-of-covid19-candidate-vaccines. ${ }^{\dagger} \mathrm{IM}$ : intramuscular, ID: intradermal, IV: intravenuous, SC: subcutaneous, IN: intranasal. 


\subsection{Convalescent plasma against SARS-CoV-2/COVID-19}

Convalescent plasma can be used to treat COVID-19 patients. The source of convalescent plasma is from the donors who has recovered from COVID-19 infection. However, some requirements must be eligible for the donors. For example, the donor must has no symptoms of COVID-19 for at least 14 days and has enough high titer of neutralization antibodies (Ripoll et al., 2021). A multi-center randomized controlled trial was held to evaluate the efficacy, safety and dose response of convalescent plasma transfusion in severe COVID-19 patients and built up a standardized protocol for the treatment (Chowdhury et al., 2020). Not only convalescent plasma is used for the treatment of the COVID-19 patients, but can also be used for the prophylaxis of normal individual (Montelongo-Jauregui et al., 2020). For example, administration of convalescent plasma in COVID-19 high risk group will prompt to prevent infection while in infected patients will reduce symptom and mortality (Sheervalilou et al., 2021; Wang et al., 2021b).

There are still some limitations and risks on using convalescent plasma. First, not all the COVID-19 patients had high enough titer of neutralization antibody in the serum. Second, the plasma of the patients may contain unknown pathogens that have risk to infect recipients. Third, antibody may cause antibody dependent enhancement (ADE) or activate the complement reaction or inflammatory on patients (de Alwis et al., 2020; Fleming and Raabe, 2020; Lutz, 2012; Yager, 2020).

\subsection{Monoclonal antibody (MAb) against SARS-CoV-2/COV- ID-19}

For seeking specific MAbs for the treatment of COVID-19 patients. Different strategies to develop MAb are employed. Ho's group studied the antibody response of COVID-19 patients and they showed that the neutralization antibody titers were higher in severe cases (Wang et al., 2020). For seeking MAbs from the patients, they sorted the memory B cells from patients' peripheral blood lymphocytes. They isolated sixty-one MAbs from five patients successfully. Nine of the MAbs had the potency to inhibit virus infectivity. The antigenic specificity of these MAbs was receptor binding domain or $\mathrm{N}$-terminal domain of $\mathrm{S}$ protein and have good neutralization ability on SARS-CoV-2 (Liu et al., 2020a).

In order to develop a universal vaccine and MAb against SARSCoV-2 and the variants, Liao's group used the highly conserved region of S protein sequences and designed a monoglycosylated $\mathrm{S}$ protein (Smg). They used this Smg to immunize mice and found that the antibodies could neutralize UK and South Africa variants. In addition, MAb produced by this Smg protein could also neutralize wild type and variants of SARS-CoV-2 (Liao et al., 2021).

The most advantage of MAb is very specific to target the virus. However, when the virus product variants, the efficacy of the MAb will decrease rapidly. In addition, MAb is not recommended for all cases of COVID-19 patients. For instant, only patients with mild to moderate COVID-19 patients who might progress to severe COVID-19 cases would recommended to receive MAb therapy. These patients usually had underlined diseases, overweight or cancer (Kim et al., 2021; Puing et al., 2021).

\section{Anti-virus drug development}

During the pandemic of COVID-19, there are no FDA-approved antiviral drugs available for treatment of the patients, especially for the emergency use in the serious cases. Therefore, the most rapid therapeutic method is trying to use the already existed antiviral drugs that may have potential to apply to COVID-19 patients. We are going to describe the properties of these current antiviral drugs and their potential effect on COVID-19 therapy.

\subsection{Camostat mesilate (CM)}

$\mathrm{CM}$ was a cysteine protease inhibitor that has been developed since 1980s in Japan. CM was a drug to treat the acute symptom of chronic pancreatitis in patients in the past. Former studies indicated that CM had the potential against SARS-CoV-1, MERS-CoV and Ebola virus on mouse model (Zhou et al., 2015). For SARSCoV-2, CM blocked TMPRSS2, a serine protease on the host's cell membrane and blocked the entry of the virus into the cytoplasm (Breining et al., 2021; Maggio and Corsini, 2020; Uno, 2020).

\subsection{Hydroxychloroquine/chloroquine}

Chloroquine or a less toxic derivative, hydroxychloroquine is an anti-malaria drug. Chloroquine or hydroxychloroquine also have anti-inflammatory and immuno-modulation effects and have broadly used for rheumatic diseases such as lupus erythematosus (Sinha and Balayla, 2020). Several studies indicated that CQ and HCQ have anti-viral activity on SARS-CoV-2 in vitro experiments (Liu et al., 2020a; Pastick et al., 2020). The mechanism associated on inhibition of endosome fusion (Principi and Esposito, 2020). However, a systemic review and meta-analysis by searching $12 \mathrm{ob}-$ servational and 3 randomized trials for the effect of CQ and HCQ. They concluded that CQ and HCQ did not improve the clinical outcomes of COVID-19 patients (Elavarasi et al., 2020).

\subsection{Arbidol (Umifenovir)}

Arbidol, or the other name, umifenovir was developed in Russia. It had a broad spectrum antiviral drug and it currently used in Russia and China. Arbidol possessed anti-viral activities against a broad spectrum of DNA and RNA viruses, such as influenza viruses, respiratory syncytial virus, parainfluenza virus, SARSCoV-1, adenovirus, poliovirus, coxsackievirus, rhinovirus, Zika virus, and hepatitis $\mathrm{B}$ and $\mathrm{C}$ viruses. The action of arbidol was inhibition of the fusion process between the virus and the host's cell membrane (Nojomi et al., 2020). For COVID-19, arbidol was shown to inhibit the release of the virus from the host cells (Zheng et al., 2020).

\subsection{Lopinavir/ritonavir}

Ritonavir and lopinavir, an improved version of ritonavir, were HIV protease inhibitor. Coformulated Lopinavir/Ritonavir was applied for a part of combination therapy on AIDS patients (Cvetkovic and Goa, 2003). It was a proposed drug for treatment of COVID-19 via binding the $3 \mathrm{C}$-like protease of SARS-CoV-2 (Nutho et al., 2020). However, several clinical researches showed that lopinavir/ ritonavir was not associated with reduction of clinical outcomes of COVID-19 patients (Horby et al., 2020; Stower, 2020). In contrast, a meta-analysis in 2020 reported that lopinavir/ritonavir still improve the outcomes on COVID-19 patients (Verdugo-Paiva et al., 2020). 


\subsection{Favipiravir}

Favipiravir was developed for the treatment on influenza virus initially. It is a prodrug which is converted to active favipiravir ribofuranosyl-5B-triphosphate (favipiravir-RTP) via intracellular phosphoribosylation. Based on its structure a nucleoside analog. Favipiravir acts as a competitor on viral RNA replication and inhibit viral RNA-dependent RNA polymerase (Ghasemnejad-Berenji and Pashapour, 2021; Joshi et al., 2021). There are several clinical trials are held in different countries on COVID-19 treatment. However, systematic reviews indicated that favipiravir had certain adverse effects such as hyperuricaemia, teratogenicity and QTc prolongation, etc. The safety of favipiravir would still require more studies to evaluate its safety especially to the COVID-19 patients (Pilkington et al., 2020; Udwadia et al., 2021).

\subsection{Remdesivir}

Remdesivir is an adenosine analog prodrug. It blocks the viral RNA replication by competing normal nucleotides to cooperate into the newly synthesized viral genomic RNA (Jorgensen et al., 2020). In animal studies, pretreatment of remdesivir on rhesus monkeys could protect them from MERS-CoV infection. It also protected African green monkeys from Nipah virus infection and rhesus monkeys dying from Ebola virus (Aleissa et al., 2020; Malin et al., 2020). During the pandemic, remdesivir was one of the potential drugs administered to COVID-19 patients on clinical trials (Beigel et al., 2020; Young et al., 2021).

\subsection{Molnupiravir}

Molnupiravir is a newly oral antiviral drugs also initially developed for influenza viruses. It had antiviral effect on multiple RNA viruses such as various coronaviruses, respiratory viruses, togaviruses and Ebola virus (Painter et al., 2021a). Its action acts as a ribonucleoside analog and itself will be incorporated into viral RNA, induced SARS-CoV-2 to form mutagenesis and caused blockade of viral genome RNA replication (Gordon et al., 2021; Kabinger et al., 2021). It was demonstrated that molnupiravir reduced viral load on SARS-CoV-2 infected animal experiments including Syrian hamster model, infected ferrets model and humanized mouse model. Molnupiravir have demonstrated good tolerability and doseproportional pharmacokinetics in phase 1 clinical trial (Painter et al., 2021b). Molnupiravir is also used for evaluation for the treatment of COVID-19 in phase 2 clinical trial (Abdelnabi et al., 2021).

\subsection{Paxlovid}

Paxlovid was the second newly oral antiviral drugs against COVID-19. The components of paxlovid contains mainly PF-07321332 (nirmatrelvir), and a combination of low dose of ritonavir. The action of PF-07321332 acts as a 3-C like protease inhibitor against SARS-CoV-2. (Mahase, 2021b). More importantly, Paxlovid has been proved to be effective on different SAR-CoV variants (Ullich et al., 2021). The phase 3 clinical trial of paxlovid is still ongoing.

\subsection{Combination therapy}

Besides using a single antiviral drug for COVID-19 therapy, combination of different antiviral drugs have been reported to treat
COVID-19 patients. Combination of remdesivir and ivermectin, an antiparasitic drug was shown synergic antiviral effect against murine hepatitis virus, a surrogate model of SARS-CoV-2 (Tan et al., 2021). The combination of hydroxychloroquine plus azithromycin indicated that the treatment could reduce in-hospital morbidity, mortality, clinical outcome and duration of hospitalization (Davido et al., 2020). However, systemic review and meta-analysis concluded that the combination of hydroxychloroquine plus azithromycin did not improve the clinical status of the patients (Cavalcanti et al., 2020). A cohort study even showed that hydroxychloroquine combined with azithromycin would increase risk of mortality when compared with single used of hydroxychloroquine (Sbidian et al., 2020). It required more studies to warrant their antiviral effect on COVID-19 patients. Besides combination of different antiviral drugs for the therapy of COVID-19, antiviral drug combined with immunomodulatory drugs have been reported. One example is the early administration of lopinavir/ritonavir and interferon has shown to shorten the virus shedding in COVID-19 patients (Zuo et al., 2020). Similar treatment by using interferon beta-1a with lopinavir-ritonavir could reduce risk of death on patients (Baghaei et al., 2021). A combination of favipiravir and an interleukin-6 receptor blocker (tocilizumab) showed significantly improve pulmonary inflammation and reduce mortality (Zhao et al., 2021). Combination of traditional Chinese medicine (TCM) with antiviral drug has also been reported. Lianhuaqingwen, a TCM formula and arbidol was reported to accelerate recovery rate and improved prognosis of moderate COVID-19 patients (Fang et al., 2020).

\subsection{Nutraceuticals}

In spite of antiviral drugs discovery and development, numerous potential anti-covid-19 natural bioactive compounds were massively revised in recent publications. These compounds originated from herbal plants, food supplement and nutraceuticals. In Wong's recent publication, a collection of functional food/nutraceuticals (i.e. probiotics, fish oil, curcumin, etc.) and micronutrients (i.e. vitamins, minerals, etc.) might have the potential to suppress COVID-19 infection by improvement of immunity and anti-inflammation (Lordan et al., 2021; Wong et al., 2021). Noticeably, some plant protease inhibitors of several food products might have the potential to suppress COVID-19 replication (Savant et al., 2021). However, clinical trials were essential to prove the authentic effect of these bioactive compounds from food and related supplements in future.

Table 3 summarized the potential antiviral drugs on COVID-19 treatment and Figure 1 represents the overview of the main axis of this review, highlighting the main strategies for the treatment and prevention on COVID-19 infection, and the evolution of the SARS-CoV-2.

\section{Conclusion and future perspective}

In order to develop effective vaccines and antiviral drugs simultaneously, more effort must be use to realize the SARS-CoV-2 including its replication, virus-host interaction, pathogenesis based on fundamental research. However, not a single strategy can eradicate the COVID-19 pandemic completely. For the treatment of patients, combination therapy of antiviral drug and cytokine therapy may be a rational approach in order to improve the prognosis and also reduce the mortality. For prevention, global vaccination to in- 
Table 3. : Potential antiviral drugs on COVID-19 treatment

\begin{tabular}{llll}
\hline Name of drugs & Origin use & Mode of Action on SARS-CoV-2 & $\begin{array}{l}\text { Current situation } \\
\text { on COVID-19* }\end{array}$ \\
\hline Camostat mesilate & $\begin{array}{l}\text { Relieve symptom of } \\
\text { chronic pancreatitis }\end{array}$ & Blockade of TMPRSS2 & ND \\
$\begin{array}{l}\text { Hydroxychloroquine/chloroquine } \\
\text { Arbidol (Umifenovir) }\end{array}$ & $\begin{array}{l}\text { Anti-malaria drug } \\
\text { Broad spectrum antiviral drugs }\end{array}$ & $\begin{array}{l}\text { Inhibition of endosome fusion } \\
\text { Inhibition of virus releasing }\end{array}$ & No benefit in clinical trials \\
Lopinavir/Ritonavir & Anti-retroviral drug & Inhibit 3C-like protease & No benefit in clinical trials \\
Favipiravir & Anti-influenza virus drug & Nucleoside analog, inhibit viral & $\begin{array}{l}\text { No evidence of SARS- } \\
\text { CoV-2 inactivation }\end{array}$ \\
Remdesivir & Viral polymerase inhibitor & $\begin{array}{l}\text { RNA-dependent RNA polymerase } \\
\text { RNA-dependent RNA polymerase }\end{array}$ & $\begin{array}{l}\text { Approved, but weakly } \\
\text { effective in clinical trials } \\
\text { Molnupiravir }\end{array}$ \\
Anti-influenza virus drug & Nucleoside analog, inhibit viral & $\begin{array}{l}\text { Under investigation, } \\
\text { approved }\end{array}$ \\
Paxlovid & RNA-dependent RNA polymerase & Inhibit 3C-like protease & Under investigation \\
\hline
\end{tabular}

*Part of the information is adopted from https://viralzone.expasy.org/9078.

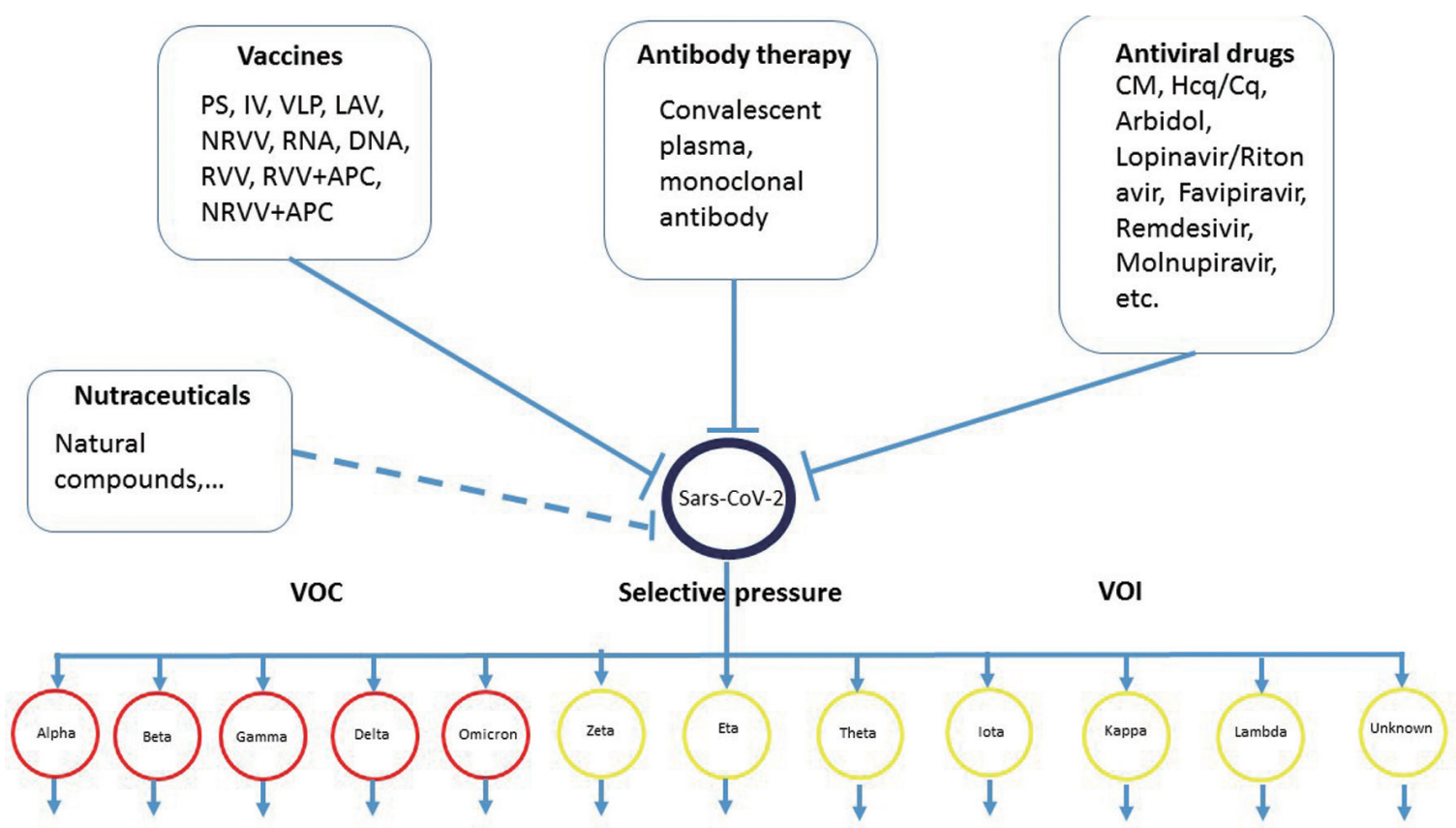

Figure 1. Overview the main axis of this review, summarizes the main strategies for the treatment and prevention on COVID-19 infection, and the evolution of the SARS-CoV-2.

crease herd immunity is a right direction. To date, there are more than two hundred vaccines are on-going for subclinical trial and clinical trials on different phases. Some of the vaccines has been approved based on emergency use authorization (EUA) by WHO. However, examples of immunological breakthrough of the virus on completely vaccinated individual has been reported. In order to avoid repeating vaccination due to the virus variants emerging, it is reasonable to develop a universal vaccine. Discovery of new anti-viral drugs against SARS-CoV-2 is also essential at the same time. While the coverage of the vaccination and immune status is continuing to increase in human being, the virus is also evolving into more and more variants. Therefore, learning how to living with the virus may be the best ending.
References

Abdelnabi, R., Foo, C.S., Kaptein, S.J., Zhang, X., Langendries, L., Vangeel, L., Vergote, V., Heylen, E., Leyssen, P., and Dallmeier, K. (2021). Molnupiravir (EIDD-2801) inhibits SARS-CoV-2 replication and enhances the efficacy of favipiravir in a Syrian hamster infection model. bioRxiv. Aleem, A., Akbar Samad, A.B., and Slenker, A.K. (2021). Emerging Variants of SARS-CoV-2 And Novel Therapeutics Against Coronavirus (COVID-19). StatPearls Publishing LLC, Treasure Island (FL).

Aleissa, M.M., Silverman, E.A., Paredes Acosta, L.M., Nutt, C.T., Richterman, A., and Marty, F.M. (2020). New Perspectives on Antimicrobial Agents: Remdesivir Treatment for COVID-19. Antimicrob. Agents Chemother. 65(1): e01814-20.

Arav, Y., Fattal, E., and Klausner, Z. (2021). Increased transmissibility of 
emerging SARS-CoV-2 variants is driven either by viral load or probability of infection rather than environmental stability. medRxiv.

Ariamanesh, M., Porouhan, P., PeyroShabany, B., Fazilat-Panah, D., Dehghani, M., Nabavifard, M., Hatami, F., Fereidouni, M., Welsh, J.S., and Javadinia, S.A. (2021). Immunogenicity and Safety of the inactivated SARS-CoV-2 vaccine (BBIBP-CorV) in patients with malignancy. Cancer Invest.

Baghaei, P., Dastan, F., Marjani, M., Moniri, A., Abtahian, Z., Ghadimi, S., Valizadeh, M., Heshmatnia, J., Mirenayat, M.S., and Abedini, A (2021). Combination therapy of IFN $\beta 1$ with lopinavir-ritonavir, in creases oxygenation, survival and discharging of sever COVID-19 infected inpatients. Int. Immunopharmacol. 92: 107329.

Bahrami, A., and Ferns, G.A. (2020). Genetic and pathogenic characterization of SARS-CoV-2: a review. Future Virol. 15(8): 533-549.

Beigel, J.H., Tomashek, K.M., Dodd, L.E., Mehta, A.K., Zingman, B.S., Kalil, A.C., Hohmann, E., Chu, H.Y., Luetkemeyer, A., and Kline, S. (2020). Remdesivir for the treatment of Covid-19. N. Engl. J. Med. 383: 18131826.

Breining, P., Frølund, A.L., Højen, J.F., Gunst, J.D., Staerke, N.B., Saedder, E. Cases-Thomas, M., Little, P., Nielsen, L.P., Søgaard, O.S., and Kjolby, M. (2021). Camostat mesylate against SARS-CoV-2 and COVID-19-Rationale, dosing and safety. Basic Clin. Pharmacol. Toxicol. 128(2): 204-212.

Burgos-Salcedo, J.D. (2021). A Comparative Analysis of Clinical Stage 3 COVID-19 Vaccines using Knowledge Representation. medRxiv.

Cao, Q., Wu, S., Xiao, C., Chen, S., Chi, X., Cui, X., Tang, H., Su, W., Zheng, Y., and Zhong, J. (2021). Integrated single-cell analysis revealed immune dynamics during Ad5-nCoV immunization. Cell Discov. 7: 1-17.

Cavalcanti, A.B., Zampieri, F.G., Rosa, R.G., Azevedo, L.C., Veiga, V.C., Avezum, A., Damiani, L.P., Marcadenti, A., Kawano-Dourado, L., and Lisboa, T. (2020). Hydroxychloroquine with or without azithromycin in mild-to-moderate Covid-19. N. Engl. J. Med. 383: 2041-2052.

Chagla, Z. (2021). The BNT162b2 (BioNTech/Pfizer) vaccine had 95\% efficacy against COVID-19 $\geq 7$ days after the 2 nd dose. Ann. Intern. Med. 174: JC15.

Chakraborty, C., Bhattacharya, M., and Sharma, A.R. (2021a). Present variants of concern and variants of interest of severe acute respiratory syndrome coronavirus 2: Their significant mutations in S-glycoprotein, infectivity, re-infectivity, immune escape and vaccines activity. Rev. Med. Virol. e2270.

Chakraborty, C., Ranjan, A., Bhattacharya, M., Agoramoorthy, G., and Lee, S-S. (2021b). The current second wave and COVID-19 vaccination status in India. Brain Behav. Immun. 96: 1-4.

Chen, J., Wang, R., Gilby, N.B., and Wei, G-W. (2021). Omicron (B. 1.1. 529): Infectivity, vaccine breakthrough, and antibody resistance. arXiv.

Choo, S.Z.L., and Teo, S.P. (2021). Gam-COVID-Vac (Sputnik V): a heterologous adenoviral vector-based COVID-19 vaccine. Aging Pathobiol. Ther. 3(2): 43-45.

Chowdhury, F.R., Hoque, A., Chowdhury, F.U.H., Amin, M.R., Rahim, A., Rahman, M.M., Yasmin, R., Amin, M.R., Miah, M.T., Kalam, M.A., and Rahman, M.S. (2020). Convalescent plasma transfusion therapy in severe COVID-19 patients- a safety, efficacy and dose response study: A structured summary of a study protocol of a phase II randomized controlled trial. Trials 21(1): 883

Ciotti, M., Angeletti, S., Minieri, M., Giovannetti, M., Benvenuto, D., Pascarella, S., Sagnelli, C., Bianchi, M., Bernardini, S., and Ciccozzi, M. (2019). COVID-19 Outbreak: An Overview. Chemotherapy 64: 215223.

Cvetkovic, R.S., and Goa, K.L. (2003). Lopinavir/ritonavir: a review of its use in the management of HIV infection. Drugs 63(8): 769-802.

Davido, B., Lansaman, T., Lawrence, C., Alvarez, J-C., Bouchand, F., Moine, P., Perronne, V., Le Gal, A., Annane, D., and Perronne, C. (2020). Hydroxychloroquine plus azithromycin: a potential interest in reducing in-hospital morbidity due to COVID-19 pneumonia (HI-ZY-COVID)? medRxiv.

de Alwis, R., Chen, S., Gan, E.S., and Ooi, E.E. (2020). Impact of immune enhancement on Covid-19 polyclonal hyperimmune globulin therapy and vaccine development. EBioMedicine 55: 102768

Duong, D. (2021). Alpha, Beta, Delta, Gamma: What's important to know about SARS-CoV-2 variants of concern? Can. Med. Assoc. J. 193(27): E1059-E1060.

Elavarasi, A., Prasad, M., Seth, T., Sahoo, R.K., Madan, K., Nischal, N.,
Soneja, M., Sharma, A., Maulik, S.K., Shalimar, and Garg, P. (2020) Chloroquine and Hydroxychloroquine for the Treatment of COVID-19: a Systematic Review and Meta-analysis. J. Gen. Intern. Med. 35: 3308-3314.

Eskier, D., Karakülah, G., Suner, A., and Oktay, Y. (2020). RdRp mutations are associated with SARS-CoV-2 genome evolution. PeerJ 8: e9587.

Fang, J., Li, H., Du, W., Yu, P., Guan, Y.Y., Ma, S.Y., Liu, D., Chen, W., Shi, G.C. and Bian, X.L. (2020). Efficacy of early combination therapy with lianhuaqingwen and arbidol in moderate and severe COVID-19 patients: a retrospective cohort study. Front. Pharmacol. 11: 1465.

Ferraz, M.V., Moreira, E.G., Coêlho, D.F., Wallau, G.L., and Lins, R.D. (2021). Immune evasion of SARS-CoV-2 variants of concern is driven by low affinity to neutralizing antibodies. Chem. Commun. 57: 6094-6097.

Fleming, A.B., and Raabe, V. (2020). Current studies of convalescent plasma therapy for COVID-19 may underestimate risk of antibody-dependent enhancement. J. Clin. Virol. 127: 104388.

Fung, T.S., and Liu, D.X. (2019). Human coronavirus: host-pathogen interaction. Annu. Rev. Microbiol. 73: 529-557.

Gao, R., Zu, W., Liu, Y., Li, J., Li, Z., Wen, Y., Wang, H., Yuan, J., Cheng, L., and Zhang, S. (2021). Quasispecies of SARS-CoV-2 revealed by single nucleotide polymorphisms (SNPs) analysis. Virulence 12(1): 1209-1226.

Ghasemnejad-Berenji, M., and Pashapour, S. (2021). Favipiravir and COVID-19: A Simplified Summary. Drug Res. 71: 166-170.

Gordon, C.J., Tchesnokov, E.P., Schinazi, R.F., and Götte, M. (2021). Molnupiravir promotes SARS-CoV-2 mutagenesis via the RNA template. J. Biol. Chem. 297(1): 100770.

Gupta, A., Karki, R., Dandu, H.R., Dhama, K., Bhatt, M.L., and Saxena, S.K. (2020). COVID-19: benefits and risks of passive immunotherapeutics. Hum. Vaccin. Immunother. 16: 2963-2972.

Haidere, M.F., Ratan, Z.A., Nowroz, S., Zaman, S.B., Jung, Y.J., Hosseinzadeh, H., and Cho, J.Y. (2021). COVID-19 vaccine: critical questions with complicated answers. Biomol. Ther. (Seoul) 29(1): 1-10.

He, X., Hong, W., Pan, X., Lu, G., and Wei, X. (2021). SARS-CoV-2 Omicron variant: characteristics and prevention. MedComm. 2: 838-845.

Heath, P.T., Galiza, E.P., Baxter, D.N., Boffito, M., Browne, D., Burns, F., Chadwick, D.R., Clark, R., Cosgrove, C., and Galloway, J. (2021). Safety and efficacy of NVX-CoV2373 Covid-19 vaccine. N. Engl. J. Med. 385: 1172-1183.

Heinz, F.X., and Stiasny, K. (2021). Profiles of current COVID-19 vaccines. Wien. Klin. Wochenschr. 133(7): 271-283.

Horby, P.W., Mafham, M., Bell, J.L., Linsell, L., Staplin, N., Emberson, J. Palfreeman, A., Raw, J., Elmahi, E., and Prudon, B. (2020). Lopinavir ritonavir in patients admitted to hospital with COVID-19 (RECOVERY): a randomised, controlled, open-label, platform trial. Lancet 396(10259): 1345-1352.

Hsieh, S.M., Liu, M.C., Chen, Y.H., Lee, W.S., Hwang, S.J., Cheng, S.H., Ko, W.C., Hwang, K.P., Wang, N.C., Lee, Y.L., Lin, Y.L., Shih, S.R., Huang C.G., Liao, C.C., Liang, J.J., Chang, C.S., Chen, C., Lien, C.E., Tai, I.C., and Lin, T.Y. (2021). Safety and immunogenicity of CpG 1018 and aluminium hydroxide-adjuvanted SARS-CoV-2 S-2P protein vaccine MVCCOV1901: A large-scale double-blind, randomised, placebo-controlled phase 2 trial. Lancet Respir. Med. 9(12): 1396-1406.

Huang, C., Wang, Y., Li, X., Ren, L., Zhao, J., Hu, Y., Zhang, L., Fan, G., Xu J., and Gu, X. (2020). Clinical features of patients infected with 2019 novel coronavirus in Wuhan, China. Lancet 395(10223): 497-506.

Jary, A., Leducq, V., Malet, I., Marot, S., Klement-Frutos, E., Teyssou, E., Soulié, C., Abdi, B., Wirden, M., and Pourcher, V. (2020). Evolution of viral quasispecies during SARS-CoV-2 infection. Clin. Microbiol. Infect. 26(11): 1560.e1-1560.e4.

Jorgensen, S.C.J., Kebriaei, R., and Dresser, L.D. (2020). Remdesivir: Review of Pharmacology, Pre-clinical Data, and Emerging Clinical Experience for COVID-19. Pharmacotherapy 40(7): 659-671.

Joshi, S., Parkar, J., Ansari, A., Vora, A., Talwar, D., Tiwaskar, M., Patil, S., and Barkate, H. (2021). Role of favipiravir in the treatment of COVID-19. Int. J. Infect. Dis. 102: 501-508.

Kabinger, F., Stiller, C., Schmitzová, J., Dienemann, C., Kokic, G., Hillen, H.S., Höbartner, C., and Cramer, P. (2021). Mechanism of molnupiravirinduced SARS-CoV-2 mutagenesis. Nat. Struct. Mol. Biol. 28: 740-746.

Kim, S.B., Kim, J., Huh, K., Choi, W.S., Kim, Y.J., Joo, E.J., Kim, Y.J., Yoon, Y.K., Heo, J.Y., Seo, Y.B., Jeong, S.J., Yu, S.Y., Peck, K.R., Choi, M., Yeom, J.S., and Korean Society of Infectious Diseases (KSID). (2021). Korean So- 
ciety of Infectious Diseases/National Evidence-based Healthcare Collaborating Agency Recommendations for anti-SARS-CoV-2 monoclonal antibody treatment of patients with COVID-19. Infect. Chemother 53(2): 395-403.

Kimura, I., Kosugi, Y., Wu, J., Yamasoba, D., Butlertanaka, E.P., Tanaka, Y.L., Liu, Y., Shirakawa, K., Kazuma, Y., and Nomura, R. (2021). SARS-CoV-2 Lambda variant exhibits higher infectivity and immune resistance. bioRxiv.

Knoll, M.D., and Wonodi, C. (2021). Oxford-AstraZeneca COVID-19 vaccine efficacy. Lancet 397(10269): 72-74.

Konings, F., Perkins, M.D., Kuhn, J.H., Pallen, M.J., Alm, E.J., Archer, B.N., Barakat, A., Bedford, T., Bhiman, J.N., and Caly, L. (2021). SARS-CoV-2 Variants of Interest and Concern naming scheme conducive for global discourse. Nat. Microbiol. 6: 821-823.

Kumar, V., Singh, J., Hasnain, S.E., and Sundar, D. (2021). Possible Link between Higher Transmissibility of Alpha, Kappa and Delta Variants of SARS-CoV-2 and Increased Structural Stability of Its Spike Protein and hACE2 Affinity. Int. J. Mol. Sci. 22(17): 9131.

Liao, H.Y., Huang, H.Y., Chen, X., Cheng, C.W., Wang, S.W., Shahed-Al-Mahmud, M., Chen, T.H., Lo, J.M., Liu, Y.M., and Ma, H.H. (2021). Impact of Glycosylation on SARS-CoV-2 Infection and Broadly Protective Vaccine Design. bioRxiv.

Liu, L., Wang, P., Nair, M.S., Yu, J., Rapp, M., Wang, Q., Luo, Y., Chan, J.F., Sahi, V., Figueroa, A., Guo, X.V., Cerutti, G., Bimela, J., Gorman, J., Zhou, T., Chen, Z., Yuen, K.Y., Kwong, P.D., Sodroski, J.G., Yin, M.T., Sheng, Z., Huang, Y., Shapiro, L., and Ho, D.D. (2020a). Potent neutralizing antibodies against multiple epitopes on SARS-CoV-2 spike. Nature 584: 450-456.

Liu, X., Chen, H., Shang, Y., Zhu, H., Chen, G., Chen, Y., Liu, S., Zhou, Y., Huang, M., Hong, Z., and Xia, J. (2020b). Efficacy of chloroquine versus lopinavir/ritonavir in mild/general COVID-19 infection: a prospective, open-label, multicenter, randomized controlled clinical study. Trials 21: 622.

Lordan, R., Rando, H.M., and Greene, C.S. (2021). Dietary supplements and nutraceuticals under investigation for COVID-19 prevention and treatment. Msystems 6: e00122-00121.

Lu, R., Zhao, X., Li, J., Niu, P., Yang, B., Wu, H., Wang, W., Song, H., Huang, B., and Zhu, N. (2020). Genomic characterisation and epidemiology of 2019 novel coronavirus: implications for virus origins and receptor binding. Lancet 395(10224): 565-574.

Lutz, H.U. (2012). How immune complexes from certain IgG NAbs and any F $\left(a b^{\prime}\right) 2$ can mediate excessive complement activation. Adv. Exp. Med. Biol. 750: 186-196.

Maggio, R., and Corsini, G.U. (2020). Repurposing the mucolytic cough suppressant and TMPRSS2 protease inhibitor bromhexine for the prevention and management of SARS-CoV-2 infection. Pharmacol. Res. 157: 104837.

Mahase, E. (2021a). Covid-19: How many variants are there, and what do we know about them? Br. Med. J. 374: n1971.

Mahase, E. (2021b). Covid-19: Pfizer's paxlovid is $89 \%$ effective in patients at risk of serious illness, company reports. Br. Med. J. 375: n2713.

Malik, Y.A. (2020). Properties of coronavirus and SARS-CoV-2. Malays. J. Pathol. 42(1): 3-11.

Malin, J.J., Suárez, I., Priesner, V., Fätkenheuer, G., and Rybniker, J. (2020). Remdesivir against COVID-19 and other viral diseases. Clin. Microbiol. Rev. 34: e00162-00120.

Misra, S.K., Pathak, K., Pathak, D., and Yadav, R. (2021). Current updates on COVID-19 vaccines. Asian J. Pharm. Clin. Res. 5(Suppl 3): 17-23.

Montelongo-Jauregui, D., Vila, T., Sultan, A.S., and Jabra-Rizk, M.A. (2020) Convalescent serum therapy for COVID-19: A 19th century remedy for a 21st century disease. PLoS Pathog. 16: e1008735

Ndwandwe, D., and Wiysonge, C.S. (2021). COVID-19 vaccines. Curr. Opin. Immunol. 71: 111-116.

Nishikawa, T., Chang, C.Y., Tai, J.A., Hayashi, H., Sun, J., Torii, S., Ono, C., Matsuura, Y., Ide, R., and Mineno, J. (2021). Anti-CoVid19 plasmid DNA vaccine induces a potent immune response in rodents by Pyro-drive Jet Injector intradermal inoculation. bioRxiv.

Nojomi, M., Yassin, Z., Keyvani, H., Makiani, M.J., Roham, M., Laali, A., Dehghan, N., Navaei, M., and Ranjbar, M. (2020). Effect of Arbidol (Umifenovir) on COVID-19: a randomized controlled trial. BMC Infect. Dis. 20: 954
Nutho, B., Mahalapbutr, P., Hengphasatporn, K., Pattaranggoon, N.C., Simanon, N., Shigeta, Y., Hannongbua, S., and Rungrotmongkol, T. (2020). Why are lopinavir and ritonavir effective against the newly emerged coronavirus 2019? Atomistic insights into the inhibitory mechanisms. Biochemistry 59(18): 1769-1779.

Ozer, E.A., Simons, L.M., Adewumi, O.M., Fowotade, A.A., Omoruyi, E.C., Adeniji, J.A., Dean, T.J., Taiwo, B.O., Hultquist, J.F., and Lorenzo-Redondo, R. (2021). High prevalence of SARS-CoV-2 B. 1.1. 7 (UK variant) and the novel B. 1.5. 2.5 lineage in Oyo State, Nigeria. medRxiv.

Painter, G.R., Natchus, M.G., Cohen, O., Holman, W., and Painter, W.P. (2021a). Developing A Direct Acting, Orally Available Antiviral Agent in a Pandemic: The Evolution of Molnupiravir as a Potential Treatment for COVID-19. Curr. Opin. Virol. 50: 17-22.

Painter, W.P., Holman, W., Bush, J.A., Almazedi, F., Malik, H., Eraut, N.C., Morin, M.J., Szewczyk, L.J., and Painter, G.R. (2021b). Human safety, tolerability, and pharmacokinetics of molnupiravir, a novel broadspectrum oral antiviral agent with activity against SARS-CoV-2. Antimicrob. Agents Chemother. 65: e02428-02420.

Palacios, R., Patiño, E.G., de Oliveira Piorelli, R., Conde, M.T.R.P., Batista, A.P., Zeng, G., Xin, Q., Kallas, E.G., Flores, J., and Ockenhouse, C.F. (2020). double-blind, randomized, placebo-controlled phase III clinical trial to evaluate the efficacy and safety of treating healthcare professionals with the adsorbed Covid-19 (inactivated) vaccine manufactured by Sinovac-PROFISCOV: A structured summary of a study protocol for a randomised controlled trial. Trials 21: 1-3.

Panzera, Y., Goñi, N., Calleros, L., Ramos, N., Frabasile, S., Marandino, A. Tomás, G., Techera, C., Grecco, S., and Fuques, E. (2021). Genome sSequences of SARS-CoV-2 P. 1 (Variant of Concern) and P. 2 (Variant of Interest) identified in Uruguay. Microbiol. Resour. Announc. 10: e00410-00421.

Park, K.S., Sun, X., Aikins, M.E., and Moon, J.J. (2020). Non-viral COVID-19 vaccine delivery systems. Adv. Drug Deliv. Rev. 169: 137-151.

Pastick, K.A., Okafor, E.C., Wang, F., Lofgren, S.M., Skipper, C.P., Nicol, M.R., Pullen, M.F., Rajasingham, R., McDonald, E.G., Lee, T.C., Schwartz, I.S., Kelly, L.E., Lother, S.A., Mitjà, O., Letang, E., Abassi, M., and Boulware, D.R. (2020). Hydroxychloroquine and chloroquine for treatment of SARS-CoV-2 (COVID-19). Open Forum Infect. Dis. 7(4): ofaa130.

Pereira, F., Tosta, S., Lima, M.M., Reboredo de Oliveira da Silva, L., Nardy, V.B., Gómez, M.K.A., Lima, J.G., Fonseca, V., de Oliveira, T., Lourenço, J., Alcantara Jr, L.C., Giovanetti, M., and Leal, A. (2021). Genomic surveillance activities unveil the introduction of the SARS-CoV-2 B. 1.525 variant of interest in Brazil: Case Report. J. Med. Virol. 93: 5523-5526.

Pilkington, V., Pepperrell, T., and Hill, A. (2020). A review of the safety of favipiravir - a potential treatment in the COVID-19 pandemic? J. Virus Erad. 6: 45-51.

Presti, A.L., Rezza, G., and Stefanelli, P. (2020). Selective pressure on SARSCoV-2 protein coding genes and glycosylation site prediction. Heliyon 6(9): e05001.

Principi, N., and Esposito, S. (2020). Chloroquine or hydroxychloroquine for prophylaxis of COVID-19. Lancet Infect. Dis. 20: 1118.

Puing, A.G., Ho, S., Frankel, P., Tegtmeier, B., Martin, A., Ross, J., Nanayakkara, D., Dickter, J., Seto, T., Nakamura, R., Taplitz, R., and Dadwal, S. (2021). SARS-CoV-2 specific monoclonal antibody for the treatment of mild-to-moderate Covid-19 in cancer patients: A single-center experience. J. Infect. Dis. jiab406.

Qian, X.J., Wan, C.H., Zhao, P., and Qi, Z.T. (2021). Recent advances in vaccine development of severe acute respiratory syndrome coronavirus 2. Medical Journal of Chinese People's Liberation Army 46(7): 710717.

Ripoll, J.G., van Helmond, N., Senefeld, J.W., Wiggins, C.C., Klassen, S.A., Baker, S.E., Larson, K.F., Murphy, B.M., Andersen, K.J., Ford, S.K., Casadevall, A., and Joyner, M.J. (2021). Convalescent Plasma for Infectious Diseases: Historical Framework and Use in COVID-19. Clin. Microbiol. Newsl. 43: 23-32.

Romero, P.E., Dávila-Barclay, A., Salvatierra, G., González, L., Cuicapuza, D., Solis, L., Marcos-Carbajal, P., Huancachoque, J., Maturrano, L., and Tsukayama, P. (2021). The emergence of SARS-CoV-2 variant lambda (C. 37$)$ in South America. medRxiv.

Ryzhikov, A., Ryzhikov, E., Bogryantseva, M., Usova, S., Danilenko, E., Nechaeva, E., Pyankov, O., Pyankova, O., Gudymo, A., and Bodnev, S. (2021). A single blind, placebo-controlled randomized study of the 
safety, reactogenicity and immunogenicity of the "EpiVacCorona" Vaccine for the prevention of COVID-19, in volunteers aged 18-60 years (phase I-II). Russian J. Infect. Immunity 11: 283-296.

Sadoff, J., Le Gars, M., Shukarev, G., Heerwegh, D., Truyers, C., de Groot A.M., Stoop, J., Tete, S., Van Damme, W., and Leroux-Roels, I. (2020). Safety and immunogenicity of the Ad26. COV2. S COVID-19 vaccine candidate: interim results of a phase $1 / 2$ a, double-blind, randomized, placebo-controlled trial. MedRxiv.

Savant, S., Srinivasan, S., and Kruthiventi, A.K. (2021). Potential nutraceuticals for COVID-19. Nutr. Diet. (13): 25-51.

Sbidian, E., Josse, J., Lemaitre, G., Mayer, I., Bernaux, M., Gramfort, A., Lapidus, N., Paris, N., Neuraz, A., and Lerner, I. (2020). Hydroxychloroquine with or without azithromycin and in-hospital mortality or discharge in patients hospitalized for COVID-19 infection: a cohort study of 4,642 in-patients in France. MedRxiv.

Shchelkanov, M.Y., Popova, A.Y., Dedkov, V., Akimkin, V., and Maleyev, V. (2020). History of investigation and current classification of coronaviruses (Nidovirales: Coronaviridae). Russian J. Infect. Immunity 10 221-246.

Sheervalilou, R., Shirvaliloo, M., Sargazi, S., Bahari, S., Saravani, R., Shahraki, J., Shirvalilou, S., Shahraki, O., Nazarlou, Z., Shams, Z., and Ghaznavi, H. (2021). Convalescent blood: Current perspective on the efficacy of a legacy approach in COVID-19 treatment. Blood Purif. 51: 1-14.

Shrotri, M., Swinnen, T., Kampmann, B., and Parker, E.P. (2021). An interactive website tracking COVID-19 vaccine development. Lancet Glob. Health 9: e590-e592.

Sinha, N., and Balayla, G. (2020). Hydroxychloroquine and COVID-19. Postgrad. Med. J. 96: 550-555.

Stower, H. (2020). Lopinavir-ritonavir in severe COVID-19. Nat. Med. 26: 465.

Tan, Y.L., Tan, K.S.W., Chu, J.J.H., and Chow, V.T. (2021). Combination treatment with remdesivir and ivermectin exerts highly synergistic and potent antiviral activity against murine coronavirus infection. Front. Cell. Infect. Microbiol. 11: 700502.

Tebas, P., Yang, S., Boyer, J.D., Reuschel, E.L., Patel, A., Christensen-Quick, A., Andrade, V.M., Morrow, M.P., Kraynyak, K., and Agnes, J. (2021). Safety and immunogenicity of INO-4800 DNA vaccine against SARSCoV-2: A preliminary report of an open-label, Phase 1 clinical trial. EClinicalMedicine 31: 100689.

Teo, S.P. (2021). Review of COVID-19 mRNA vaccines: BNT162b2 and mRNA-1273. J. Pharm. Pract. Res.

Trougakos, I.P., Stamatelopoulos, K., Terpos, E., Tsitsilonis, O.E., Aivalioti, E., Paraskevis, D., Kastritis, E., Pavlakis, G.N., and Dimopoulos, M.A. (2021). Insights to SARS-CoV-2 life cycle, pathophysiology, and rationalized treatments that target COVID-19 clinical complications. J. Biomed. Sci. 28: 1-18.

Udwadia, Z.F., Singh, P., Barkate, H., Patil, S., Rangwala, S., Pendse, A., Kadam, J., Wu, W., Caracta, C.F., and Tandon, M. (2021). Efficacy and safety of favipiravir, an oral RNA-dependent RNA polymerase inhibitor, in mild-to-moderate COVID-19: A randomized, comparative, open-label, multicenter, phase 3 clinical trial. Int. J. Infect. Dis. 103: 62-71.

Ullrich, S., Ekanayake, K.B., Otting, G., and Nitsche, C. (2021). Main protease mutants of SARS-CoV-2 variants remain susceptible to PF07321332. bioRxiv.

Uno, Y. (2020). Camostat mesilate therapy for COVID-19. Intern. Emerg. Med. 15: 1577-1578.
V'kovski, P., Kratzel, A., Steiner, S., Stalder, H., and Thiel, V. (2021). Coronavirus biology and replication: implications for SARS-CoV-2. Nat. Rev. Microbiol. 19: 155-170.

van Riel, D., and de Wit, E. (2020). Next-generation vaccine platforms for COVID-19. Nat. Mater. 19: 810-812.

Velavan, T.P., and Meyer, C.G. (2020). The COVID-19 epidemic. Trop. Med. Int. Health 25(3): 278-280.

Verdugo-Paiva, F., Izcovich, A., Ragusa, M., and Rada, G. (2020). Lopinavir-ritonavir for COVID-19: A living systematic review. Medwave 20 e7967.

Wang, C., Wang, Z., Wang, G., Lau, J.Y.N., Zhang, K., and Li, W. (2021a). COVID-19 in early 2021: current status and looking forward. Signal Transduct. Target Ther. 6: 1-14

Wang, P., Liu, L., Nair, M.S., Yin, M.T., Luo, Y., Wang, Q., Yuan, T., Mori, K. Solis, A.G., Yamashita, M., Garg, A., Purpura, L.J., Laracy, J.C., Yu, J., Joshua-Tor, L., Sodroski, J., Huang, Y., and Ho, D.D. (2020). SARS-CoV-2 neutralizing antibody responses are more robust in patients with severe disease. Emerg. Microbes. Infect. 9: 2091-2093.

Wang, Y., Huo, P., Dai, R., Lv, X., Yuan, S., Zhang, Y., Guo, Y., Li, R., Yu, Q., and Zhu, K. (2021b). Convalescent plasma may be a possible treatment for COVID-19: A systematic review. Int. Immunopharmacol. 91: 107262.

Wang, Y., Yang, C., Song, Y., Coleman, J.R., Stawowczyk, M., Tafrova, J., Tasker, S., Boltz, D., Baker, R., and Garcia, L. (2021c). Scalable live-attenuated SARS-CoV-2 vaccine candidate demonstrates preclinical safety and efficacy. Proc. Natl. Acad. Sci. U.S.A. 118 118(29): e2102775118.

Wong, Y., Chan, C.H., Venkatakrishnan, K., Chiu, H.F., Shen, Y.C., Glovinskaia, O., Han, Y.C., and Wang, C.K. (2021). Impact of dietary nutrients (functional foods/nutraceuticals) and micronutrients on COVID-19: A review. J. Food Bioact. 15: 29-38.

World Health Organization. (2021). Background document on the inactivated vaccine Sinovac-CoronaVac against COVID-19: background document to the WHO interim recommendations for use of the inactivated COVID-19 vaccine, CoronaVac, developed by Sinovac, 24 May 2021.

Yager, E.J. (2020). Antibody-dependent enhancement and COVID-19: moving toward acquittal. Clin. Immunol. 217: 108496.

Young, B., Tan, T.T., and Leo, Y.S. (2021). The place for remdesivir in COVID-19 treatment. Lancet Infect. Dis. 21: 20-21.

Zhang, N., Li, C., Hu, Y., Li, K., Liang, J., Wang, L., Du, L., and Jiang, S. (2020). Current development of COVID-19 diagnostics, vaccines and therapeutics. Microbes Infect. 22(6-7): 231-235.

Zhao, H., Zhu, Q., Zhang, C., Li, J., Wei, M., Qin, Y., Chen, G., Wang, K., Yu, J., Wu, Z., Chen, X., and Wang, G. (2021). Tocilizumab combined with favipiravir in the treatment of COVID-19: A multicenter trial in a small sample size. Biomed. Pharmacother. 133: 110825.

Zheng, L., Zhang, L., Huang, J., Nandakumar, K.S., Liu, S., and Cheng, K. (2020). Potential treatment methods targeting 2019-nCoV infection. Eur. J. Med. Chem. 205: 112687.

Zhou, Y., Vedantham, P., Lu, K., Agudelo, J., Carrion, R., Nunneley, J.W., Barnard, D., Pöhlmann, S., McKerrow, J.H., Renslo, A.R., and Simmons, G. (2015). Protease inhibitors targeting coronavirus and filovirus entry. Antiviral. Res. 116: 76-84.

Zuo, Y., Liu, Y., Zhong, Q., Zhang, K., Xu, Y., and Wang, Z. (2020). Lopinavir/ ritonavir and interferon combination therapy may help shorten the duration of viral shedding in patients with COVID-19: A retrospective study in two designated hospitals in Anhui, China. J. Med. Virol. 92: 2666-2674 